\title{
Leucine-Rich Repeat Kinase 2 in Parkinson's Disease: Updated from Pathogenesis to Potential Therapeutic Target
}

\author{
Jinhua Chen Ying Chen Jiali Pu \\ Department of Neurology, Second Affiliated Hospital, School of Medicine, Zhejiang University, Hangzhou, PR China
}

\section{Keywords}

Parkinson's disease - Leucine-rich repeat kinase 2 .

Mutation · Inhibitors

\begin{abstract}
Background: Parkinson's disease (PD) is characterized by the selective loss of dopaminergic neurons in the midbrain. The pathogenesis of PD is not fully understood but is likely caused by a combination of genetic and environmental factors. Several genes are associated with the onset and progression of familial PD. There is increasing evidence that leucine-rich repeat kinase 2 (LRRK2) plays a significant role in PD pathophysiology. Summary: Many studies have been conducted to elucidate the functions of LRRK2 and identify effective LRRK2 inhibitors for PD treatment. In this review, we discuss the role of LRRK2 in PD and recent progress in the use of LRRK2 inhibitors as therapeutic agents. Key Messages: LRRK2 plays a significant role in the pathophysiology of PD, and pharmacological inhibition of LRRK2 has become one of the most promising potential therapies for PD. Further research is warranted to determine the functions of LRRK2 and expand the applications of LRRK2 inhibitors in PD treatment.
\end{abstract}

๑) 2018 S. Karger AG, Basel

\section{Introduction}

First described by James Parkinson in 1817 [1], Parkinson's disease (PD) is the second most common neurodegenerative disorder after Alzheimer's disease (AD), with an incidence of $1.7 \%$ in individuals aged over 65 years [2]. $\mathrm{PD}$ is characterized by the selective loss of dopaminergic (DA) neurons in the substantia nigra pars compacta $(\mathrm{SNpc})$ of the midbrain. Although several clinical approaches, including levodopa treatment and deep brain stimulation, are currently used to manage the symptoms of PD, these methods do not slow or stop disease progression. Therefore, elucidation of the mechanisms underlying PD pathogenesis, to predict disease onset and provide scientific guidance for targeted therapy, is essential.

Although the exact mechanisms underlying PD pathogenesis remain unclear, epidemiological studies have demonstrated that PD can aggregate in families [3] and that genetic factors contribute to disease development in approximately $5-10 \%$ of patients [4]. Several genes are associated with the onset and development of PD. The

J.C. and Y.C. contributed equally to this work. 
autosomal-dominant Ala53Thr mutation in the $\alpha$-synuclein (SNCA) gene on chromosome 4q22.1 was the first PD mutation identified [5]. Autosomal-dominant mutations in leucine-rich repeat kinase 2 (LRRK2) also play a significant role in PD [6]. Furthermore, 3 genes associated with autosomal-recessive PD - Parkin, PTENinduced putative kinase 1 , and protein deglycase DJ-1 were identified using gene mapping. Compared with autosomal-dominant mutations, autosomal-recessive mutations in PD genes are relatively rare [7]. Many other $\mathrm{PD}$-associated genes are associated with familial PD but their specific roles in PD pathogenesis are unknown [4].

$L R R K 2$ mutations are a common cause of late-onset autosomal-dominant PD and, to date, 7 mutations have been identified as pathogenic. The kinase and GTPase functions of LRRK2 are involved in PD pathophysiology; therefore, LRRK2 inhibition may represent a promising target for PD treatment. Recently, efforts have been made to identify LRRK2 kinase inhibitors to reduce the neural toxicity of LRRK2. In this review, we discuss the role of LRRK2 in PD pathogenesis and recent progress in the development of LRRK2 inhibitors for PD treatment.

\section{The Structure and Functions of Leucine-Rich Repeat Kinase 2}

LRRK2 encodes LRRK2, a large protein (2,527 amino acids, $286 \mathrm{kDa}$ ) containing 6 independent domains: an $\mathrm{N}$-terminal armadillo repeat region; an ankyrin repeat (ANK) domain; a leucine-rich repeat (LRR) domain; the Ras-like GTPase (ROC) domain and C-terminal domain of ROC (COR); a tyrosine kinase-like domain; and a C-terminal WD40 domain [8]. These domains of LRRK2 undergo complex interactions in the cell. Whereas the ANK, LRR, and WD40 domains are protein - protein binding domains, the kinase and GTPase domains are catalytically active domains considered to contribute to the pathological and physiological functions of LRRK2 [9]. The GTPase function of LRRK2 is mainly mediated by the ROC domain, a region characteristic of the Ras superfamily of GTPases [10] that acts as a molecular switch to regulate kinases through guanine nucleotide-dependent conformational changes [11]. The kinase domain of LRRK2 has high sequence homology to members of the receptor-interacting protein kinase and mitogen-activated protein kinase $(\mathrm{MKKK}) /$ mixed-lineage kinase families. Discovery of the most common PD-associated LRRK2 mutation, G2019S - which is located in the kinase domain and causes a 2- to 3-fold upregulation of kinase activity [12] - generated great interest in the kinase function of LRRK2 and its potential as a therapeutic target for PD [6]. To date, 2 substrates of the LRRK2 kinase domain have been identified. In 2012, Sheng et al. [13] revealed that Ser1292 autophosphorylation occurs in vivo and is enhanced by several LRRK2 mutations but blocked by exposure to a brain-penetrating LRRK2 kinase inhibitor. More recently, a subset of Rab GTPases, including Rab8A, Rab10, Rab12, and Rab7L1, were identified as LRRK2 substrates [14]. Rab8A, which is phosphorylated by LRRK2 in the Rab GTPase switch region, undergoes increased interaction with a pathological species of a-synuclein. However, the exact interplay between LRRK2, Rab GTPases, and a-synuclein remains unclear. More information on the functional substrates of the LRRK2 kinase domain and their downstream signaling pathways is essential to understand the function of LRRK2 and its role in PD.

Generally, GTPase proteins are upstream regulators of kinase proteins and their downstream signaling pathways. Regarding LRRK2, GTP binding is reportedly essential to its protein kinase activity [15]. However, this is not the only regulatory relationship between the GTPase and kinase domains of LRRK2: kinase activation is thought to regulate the GTPase functions of LRRK2. Phosphopeptide analysis and autophosphorylation site mapping have revealed that LRRK2 autophosphorylates in vitro and that several potential phosphorylation sites exist within the GTPase domain [16, 17]. Liu et al. [18] reported that GTP hydrolysis and ROC dimerization increase when the ROC domain of LRRK2 is phosphorylated by the amoeba LRRK2 orthologue ROCO4. These findings suggest that a complex functional link exists between the 2 domains. Autophosphorylation sites in the GTPase domain may yield clues regarding the mechanisms underlying LRRK2 function; thus, further studies are necessary to explore the regulatory mechanisms between the GTPase and kinase domains of LRRK2.

Other domains of LRRK2 also contribute to its function and toxicity. LRRK2 interacts with 14-3-3 proteins through its LRR domain. This interaction is dependent on several phosphorylated serines - Ser935, Ser955, and Ser973 - in the LRR domain of LRRK2 [19-21]. The 14-3-3 protein family comprises 7 conserved proteins that function in multiple cellular processes and cell survival [22]. Several pathogenic mutations reduce the interaction of LRRK2 with 14-3-3 proteins, indicating the importance of 14-3-3 proteins to LRRK2 function and toxicity $[20,23]$. Furthermore, overexpression of 14-3-3 proteins reverses the neurite shortening caused by the 
LRRK2, G2019S, and R1441G mutations in primary neurons from bacterial artificial chromosome transgenic mice [24], implying that signaling pathways that interact with LRRK2 also represent potential therapeutic targets for LRRK2-related PD.

LRRK2 is widely expressed in human tissues and may have diverse functions. In rodent brains, in-situ hybridization studies have demonstrated that $L R R K 2$ is broadly expressed throughout the brain but shows strong regional differences in expression levels, with highest expression in the striatum, cortex, and hippocampus [25]. Studies on transgenic Drosophila have suggested that LRRK2 functions in synaptic morphogenesis at the neuromuscular junction. $L R R K 2$ mutation led to impaired synaptic structures, such as expanded nerve terminals and more numerous synaptic boutons [26]. Alteration of LRRK2 activity may affect neurotransmission [26, 27]. LRRK2 is also expressed in peripheral tissues such as the kidneys, lungs, and immune tissues, where the expression levels are higher than in the brain. Accordingly, abnormal kidney structure and function are evident in LRRK2 knockout mice [28]. Additionally, LRRK2 is involved in the maturation and inflammatory response of immune cells. LRRK2 inhibition blocks the maturation of monocytes, whereas stimulation with inflammatory factors such as interferon- $\gamma$ and lipopolysaccharide increases LRRK2 expression in macrophages [29].

\section{LRRK2 Mutations and Their Mechanisms of Action}

To date, several LRRK2 mutations (including p. N1437H, p.R1441C/G/H, p.Y1699C, p.G2019S, and p.I2020T) have been identified as pathogenic [30]. Although the most common LRRK2 mutation, G2019S, accounts for just $2.2-6.6 \%$ [31] of all familial PD, it has a high prevalence in North African and Ashkenazi Jews with familial PD (41\% [32] and 30\% [33], respectively). The G2019S mutation also has a high prevalence among Ashkenazi Jews with sporadic PD, one-third of whom carry it [34]. This suggests that the G2019S mutation plays a significant role in PD pathogenesis and is a risk factor for sporadic PD. In contrast, the $\mathrm{N} 1437 \mathrm{H}$ mutation has only been reported in 2 Norwegian families [35] and 1 Swedish patient with PD [36]. These mutations have a common characteristic: they are located in catalytically active domains. The G2019S and I2020T mutations occur in the kinase domain and 5 other mutations occur in the GTPase domain, indicating that the kinase and GTPase functions of LRRK2 are critical to PD pathophysiology.
Although several LRRK2 mutations have been implicated in $\mathrm{PD}$, there is poor consensus on the specific role of LRRK2 in PD pathogenesis. The cellular functions of LRRK2 suggest that several physiological processes are involved in LRRK2-related PD. In recent years, the roles of neurite outgrowth and cytoskeletal dynamics in LRRK2related PD have garnered much attention. Several LRRK2 mutations cause a reduction in neurite growth that is rescued by LRRK2 inhibition [37-40], suggesting that LRRK2 influences the cytoskeleton. Kett et al. [41] reported that most LRRK2 mutations enhance LRRK2 oligomerization and generate microtubule-associated filamentous structures in cells. Godena et al. [42] found that LRRK2 containing ROC-COR mutations (R1441C and Y1699C) mainly binds to deacetylated microtubules and that deacetylase inhibitors and tubulin acetylase block this association. This effect was not evident with the G2019S mutation or wild-type LRRK2, implying that LRRK2 regulates microtubule stability by acting as a scaffold. LRRK2 can also directly bind to $3 \beta$-tubulin isoforms, TUBB, TUBB4, and TUBB6. This interaction is mediated by the ROC domain and is disrupted by the R1441G mutation [43]. Through this direct binding, LRRK2 may regulate tubulin acetylation and microtubule dynamics.

Besides the neurite outgrowth and cytoskeletal dynamics, LRRK2 is also implicated in intracellular vesicular trafficking. This is feasible given the interaction between LRRK2 and Rab GTPases and the role of Rab GTPases in intracellular vesicular trafficking [44]. The regulator of endocytic vesicular transport Rab5 [45] has been identified as an LRRK2-interacting protein [46]. Both overexpression and knockdown of endogenous LRRK2 in primary neuronal cells impair synaptic vesicle endocytosis but this is rescued by co-expression of functional Rab5b protein. LRRK2 also interacts with Rab7 and phosphorylates a subset of Rab GTPases, including Rab8A, Rab10, Rab12, and Rab7L1. However, the nature of these interactions and specific role of LRRK2 in intracellular vesicular trafficking remain unclear.

As mentioned earlier, LRRK2 is highly expressed in immune cells and exposure to bacterial lipopolysaccharides upregulates LRRK2 protein expression, implying that LRRK2 is involved in neuroinflammation, another important process in PD pathogenesis. Reportedly, stimulation of the toll-like receptor signaling pathway upregulates LRRK2 phosphorylation at Ser910 and Ser935 in macrophages, indicating that toll-like receptor activation is upstream of LRRK2 [47]. Increasing evidence suggests that LRRK2 is involved in the innate immune response but the underlying mechanisms are unknown. 
The relationships between LRRK2 and other cellular signaling pathways are also of interest. The $\mathrm{Wnt} / \beta$-catenin signaling pathway plays a significant role in functions of the human nervous system including synaptic differentiation, adult neurogenesis, and the protection of excitatory synaptic terminals from amyloid- $\beta$ oligomer toxicity. Therefore, the Wnt signaling pathway represents a source of therapeutic targets for the treatment of neurodegenerative diseases such as AD and PD [48]. Evidence suggests that pathogenic LRRK2 mutations influence the Wnt signaling pathways. Sancho et al. [49] reported an interaction between LRRK2 and DVL1-3, a regulator of Wnt signaling, linking LRRK2 to Wnt signaling for the first time. Berwick and Harvey [50] revealed that LRRK2 participates in canonical Wnt signaling as a scaffold, generating a bridge between membrane and cytosolic components. Under basal conditions, this scaffold forms and interacts with Wnt signaling proteins in the cytoplasm. After signal activation, it binds to the Wnt co-receptor low-density lipoprotein receptor-related protein 6 in the membrane, leading to the sequestration of Wnt signaling components. Changes in LRRK2 expression or function affect the activity of this pathway, while the protective mutation $\mathrm{R} 1398 \mathrm{H}$ has a stimulatory effect on canonical Wnt signaling [51]. Despite evidence of the relationship between LRRK2 and Wnt signaling, the specific effects of LRRK2 on downstream components remain unclear. Recently, Berwick et al. [52] reported that the primary role of LRRK2 in the canonical Wnt signaling pathway is $\beta$-catenin repression: loss of LRRK2 increases $\mathrm{Wnt} / \beta$ catenin activity, whereas overexpressed LRRK2 binds and represses $\beta$-catenin. Another study assessing the effect of LRRK2 on Wnt/planar cell polarity (PCP) signaling indicated that LRRK2 activates this pathway via interactions with multiple Wnt/PCP signaling components [53]. These opposing effects suggest that LRRK2 regulates the balance between the Wnt/ $\beta$-catenin and Wnt/PCP signaling pathways depending on its binding partner. However, the underlying mechanisms remain unclear and further studies are warranted to explore the interactions between these pathways.

Another LRRK2 mutant, I2020T, was detected in induced pluripotent stem cell-derived neurons from the Sagamihara family and demonstrated to activate the protein kinase B/glycogen synthase kinase $3 \beta$ (AKT/GSK-3 $\beta$ ) signaling pathway, leading to increased Tau phosphorylation [54].

Thus, LRRK2 is a large, complex cellular protein with various functions in the nervous system and links to several signaling pathways. To date, the exact functions of
LRRK2 in neurons remain unclear but elucidation of the biological functions of LRRK2 is essential to assess the possibility of LRRK2 inhibition for PD treatment.

\section{LRRK2 as a Therapeutic Target}

The role of LRRK2 in PD pathophysiology means that it is a promising target for PD treatment. Recently, kinase inhibitors, particularly small-molecule kinase inhibitors, have been applied in the treatment of diseases such as cancer. Thus, pharmacological inhibition targeting LRRK2 kinase function is a promising direction for PD treatment.

After confirmation of the kinase activity of LRRK2, screening of 120 kinase inhibitors was conducted. Five nonselective compounds (K252A, JAK3 inhibitor VI, staurosporine, Su-11248, and Ro-31-8220) demonstrated the ability to inhibit LRRK2 kinase activity [55]. However, these compounds have multiple kinase targets, which may result in adverse effects and limit their clinical applications. Thus, selective LRRK2 inhibitors were designed. LRRK2-IN-1, the first potent and selective LRRK2 inhibitor, rapidly suppresses LRRK2 activity through the dephosphorylation of Ser910/Ser935, abolishing 14-3-3 protein binding and the accumulation of LRRK2 in aggregate fibrillar structures [56]. In HEK293 cells containing wild-type LRRK2, LRRK2-IN-1 inhibits LRRK2 Ser910/Ser935 phosphorylation at doses of between 1 and $3 \mu \mathrm{M}$. LRRK2-IN-1 exerted similar effects on endogenous LRRK2 in human lymphoblastoid cells from patients with PD homozygous for the LRRK2 G2019S mutation, human-derived neuroblastoma SHSY5Y cells, and mouse Swiss 3T3 cells. However, in a subsequent in-vivo study, intraperitoneal injection of LRRK2-IN-1 in wildtype mice mildly inhibited LRRK2 Ser910/Ser935 phosphorylation in the brain but markedly downregulated it in the kidney, where complete inhibition of the serine biomarkers was observed at 1 and $2 \mathrm{~h}$ [56]. PD is a degenerative disease of the central nervous system and drugs targeting LRRK2 must be able to cross the blood-brain barrier (BBB) to act. Thus, the BBB is a significant barrier to drug treatment. Although LRRK2-IN-1 has a significant and highly selective effect on LRRK2 activity, its inability to permeate the BBB limits its application in vivo. Furthermore, LRRK2-IN-1 has significant off-target effects, which also impedes its application [57]. Although application of LRRK2-IN-1 for the treatment of PD is limited, it remains an effective pharmacological tool for in-vitro research. CZC-54252 and CZC-25146 [58] are 
also selective LRRK2 inhibitors that cannot cross the BBB, which limits their application. Thus, BBB penetrability is an important consideration when designing small-molecule inhibitors of LRRK2 for PD treatment.

HG-10-102-01 is the first selective LRRK2 inhibitor capable of inhibiting Ser910/Ser935 phosphorylation in the mouse brain following intraperitoneal delivery of doses as low as $50 \mathrm{mg} / \mathrm{kg}$ [59]. Its ability to inhibit LRRK2 in vivo reveals that it can cross the BBB. Since its description in 2012, several novel, selective, and brain-penetrating LRRK2 inhibitors have been described, including GSK2578215A [60], GNE-7915 [61], JH-II-127 [62], PF-06447475 [63], and MLi-2 (Table 1 for further details) [64]. These next-generation LRRK2 inhibitors exhibit improved potency, selectivity, and brain penetrability, all of which are important for clinical application. Some were also shown to exert neuroprotective effects in vitro and in vivo. GSK2578215A induces protective autophagy in the SH-SY5Y DA cell-culture model [65]. Another LRRK2 inhibitor, PF-06447475, exerted neuroprotective effects on human nerve-like differentiated cells under oxidative stress. Rotenone (ROT) introduction into nervelike differentiated cells generates in-vitro models of PD, resulting in LRRK2 phosphorylation at Ser935, nuclear condensation, increased nuclear factor $\kappa$-light-chainenhancer of activated B (NF- $\kappa \mathrm{B})$ expression, and activated caspase-3. Subsequent exposure to PF-06447475 blocks LRRK2 phosphorylation at Ser935 and reverses the apoptotic signaling activated by ROT [66]. In 2 preclinical mouse models of LRRK2 (bacterial artificial chromosome transgenic hG2019S and hR1441G), GNE-7915 was reported to enhance DA release and synaptic vesicle recycling [67]. These findings suggest that LRRK2 inhibition via small-molecule inhibitors is a promising therapeutic approach to $\mathrm{PD}$.

More recently, the biopharmaceutical company Denali Therapeutics (San Francisco, CA, USA) announced that its novel LRRK2 inhibitor, DNL201, has been tested in a healthy volunteer phase-I study. In this study, LRRK2 inhibition was measured by blood-based assays of LRRK2 phosphorylation at Ser935 and phosphorylation of the LRRK2 substrate Rab10, both of which reflect LRRK2 kinase activity. DNL201 achieved more than 90\% inhibition of LRRK2 kinase activity at peak and more than 50\% inhibition at trough drug levels. Moreover, BBB penetration of DNL201 was confirmed by the measurement of DNL201 in cerebrospinal fluid. These results indicate that DNL201 is a promising LRRK2 inhibitor and further studies on the effects of DNL201 in patients with LRRK2related PD are planned.
Given the important role of $\alpha$-synuclein in PD pathology, the relationship between LRRK2 mutations and a-synuclein has also attracted much attention. Studies have indicated that LRRK2 mutations, especially G2019S, can induce $\alpha$-synuclein-related neurotoxicity. G2019S-LRRK2 expression in cultured and DA neurons from the rat SNpc increases the recruitment of endogenous $\alpha$-synuclein into inclusions in response to a-synuclein fibril exposure [68]. Subsequent exposure to 2 LRRK2 inhibitors, MLi-2 and PF-06447475, blocks these effects. The relationship between LRRK2 and a-synuclein has also been examined in vivo. The West group built a double transgenic rat model by injecting adeno-associated viral vectors expressing $a$-synuclein into the SNpc of wild-type and G2019S-LRRK2 transgenic rats. G2019S-LRRK2 transgenic rats exhibit exacerbated inflammation and DA neurodegeneration caused by overexpression of $\alpha$-synuclein. Administration of PF06447475 ameliorates these effects and has neuroprotective effects in wild-type rats [69]. In G2019S-LRRK2 knock-in mice, Ser129-phosphorylated $\alpha$-synuclein overload at DA terminals occurs in an age-dependent manner, along with the progressive dysfunction of dopamine transporters [70]. These results reveal the significance of a-synuclein in LRRK2-related PD and the neuroprotective effects of pharmacological LRRK2 inhibition. However, the detailed relationship between $\alpha$-synuclein and LRRK2 in PD pathology remains unclear. Recently, abnormal $\alpha$-synuclein expression in peripheral nerves, for example in the enteric nervous system and skin, was described in patients with sporadic PD. In 3 patients with LRRK2-G2019S-related PD, the $\alpha$-synuclein-positive structures observed in the submucosal plexus were similar to those observed in patients with sporadic PD [71]. In this study, peripheral $\alpha$-synuclein expression did not differ between LRRK2-G2019S-related and sporadic PD, although the small number of participants may have influenced the results. Studies involving larger numbers of participants and examining more peripheral sites of a-synuclein expression in patients with LRRK2-related $\mathrm{PD}$ are warranted to reveal the relationship between peripheral $\alpha$-synuclein expression and LRRK2 mutation.

However, the development and improvement of LRRK2 inhibitors faces several challenges. First, it is difficult to test the efficacy of LRRK2 inhibitors because of a lack of appropriate preclinical models. In recent years, neurotoxins have been used to generate animal models of PD by destroying lesion-specific neurons. Although these animal models show DA neuronal loss, they fail to exhibit progressive neurodegeneration or characteristics of 
Table 1. Chemical structures and characteristics of LRRK2 inhibitors

\begin{tabular}{|c|c|c|c|c|c|c|c|}
\hline \multirow[t]{2}{*}{ LRRK2 inhibitor } & \multirow[t]{2}{*}{ Chemical structure } & \multicolumn{3}{|c|}{$\mathrm{IC}_{50}, \mathrm{~nm}$} & \multirow{2}{*}{$\begin{array}{l}\text { Kinase } \\
\text { selectivity }\end{array}$} & \multirow{2}{*}{$\begin{array}{l}\text { BBB } \\
\text { permeability }\end{array}$} & \multirow[t]{2}{*}{ Reference } \\
\hline & & WT & G2019S & A2016T & & & \\
\hline K252B & & 50 & $<200$ & $\mathrm{~N} / \mathrm{A}$ & No & $\mathrm{N} / \mathrm{A}$ & {$[55]$} \\
\hline Staurosporine & & 1 & $<5$ & $\mathrm{~N} / \mathrm{A}$ & No & N/A & {$[55]$} \\
\hline LRRK2-IN-1 & & 13 & 6 & 2450 & Yes & No & {$[56]$} \\
\hline CZC-25146 & & 4.76 & 6.87 & N/A & Yes & No & {$[58]$} \\
\hline HG-10-102-01 & & 20.3 & 3.2 & 153.7 & Yes & Yes & [59] \\
\hline GSK2578215A & & 10.9 & 8.9 & 81.1 & Yes & Yes & {$[60]$} \\
\hline
\end{tabular}


Table 1. (continued)

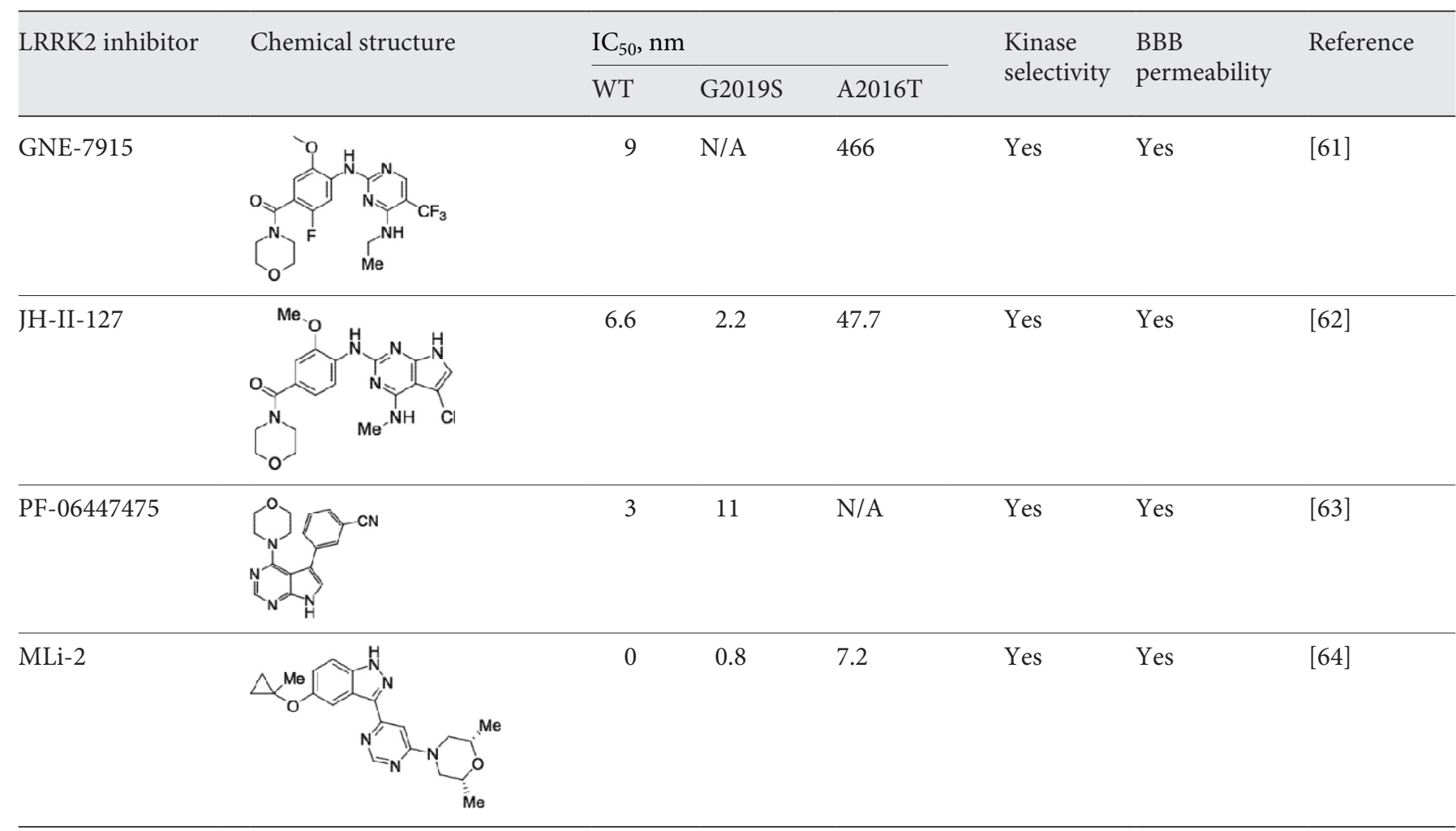

LRRK2, leucine-rich repeat kinase 2; $\mathrm{IC}_{50}$, half-maximal inhibitory concentration; WT, wild-type; BBB, blood-brain barrier; N/A, not applicable.

PD such as Lewy bodies. Considering the role of LRRK2 in PD pathophysiology, overexpression of pathogenic LRRK2 mutations using recombinant viral vectors represents a promising approach to the creation of animal models. Adenovirus-mediated expression of the G2019S LRRK2 mutation in the nigrostriatal system of adult rats induces the accumulation of neuronal ubiquitin-positive inclusions and causes progressive degeneration of nigral DA neurons compared with wild-type rats $[72,73]$. Similarly, symptoms of motor impairment, such as muscle weakness and dystonia, are evident in LRRK2 transgenic mice [74]. However, LRRK2 mutant animal models do not exhibit all the hallmarks of PD, such as Lewy bodies or DA neuron loss [75]. Moreover, the introduction of viral vectors has been proven to induce inflammatory responses and toxicity [73]. No comprehensive preclinical model completely simulates the internal environment of LRRK2-related PD; therefore, it is difficult to test the efficacy of LRRK2 inhibitors in vivo.

Safety is an essential characteristic of a clinical drug. However, LRRK2 is widely expressed in human tissues.
The loss of LRRK2 could lead to a pathological phenotype in kidney and lung tissues [76]. Administration of an LRRK2 kinase inhibitor causes a marked reduction in LRRK2 protein levels in rodents [28], implying that LRRK2 kinase inhibitors may have severe adverse effects on normal tissues. Recently, toxicology studies [77] revealed that 2 LRRK2 kinase inhibitors, GNE-7915 and GNE-0877, induce abnormal cytoplasmic accumulation of secretory lysosome-related organelles in the lungs of nonhuman primates, although no lysosomal abnormalities arise in the kidney. This suggests that pulmonary toxicity may be a critical safety concern of LRRK2 inhibitors. To date, the safety of LRRK2 inhibitors has not been clearly proven. Therefore, toxicology assessments in different animal models, especially complex mammalian models, are necessary.

Even if LRRK2 inhibitors prove effective and safe, the point at which LRRK2 inhibition should be initiated is yet to be determined. It is uncertain whether LRRK2 inhibition can stop or reverse the loss of DA neurons in the midbrain. Moreover, it is unclear whether LRRK2 inhib- 
itors can delay or stop the onset of PD in asymptomatic carriers. Thus, considering the complex disease course of PD, when and how to apply LRRK2 inhibitors merits extensive research.

\section{Conclusions}

LRRK2, a large and complex protein, plays a significant role in the pathophysiology of $\mathrm{PD}$, and mutations in the GTPase and kinase domains of LRRK2 contribute to disease progression. The GTPase and kinase domains of LRRK2 undergo complex regulatory interactions and LRRK2 can interact with several key signaling pathways within the cell. Although the results discussed in this review improve our understanding of the functions and roles of LRRK2 in $\mathrm{PD}$, the underlying mechanisms remain unclear and warrant further research. Considering the contribution of LRRK2 to PD pathophysiology, it represents one of the most promising therapeutic targets for PD treatment. Several generations of LRRK2 inhibitors have been developed, which have progressively improved in potency, selectivity, and brain penetrability. Thus, LRRK2 inhibitors may be used in clinical practice for PD treatment in future. However, their efficacy and safety remains a concern and must be addressed before their application. Further research is necessary to elucidate the functions of LRRK2 and expand its applications in PD treatment.

\section{Acknowledgments}

This work was supported by the National Natural Science Foundation of China (grant numbers 81771216, 81400933) and the Natural Science Foundation of Zhejiang Province, China (grant number LY17H090005).

\section{Disclosure Statement}

The authors declare that there is no conflict of interest regarding the publication of this article and the funding that they have received.

\section{References}

1 Parkinson J: An essay on the shaking palsy. 1817. J Neuropsychiatry Clin Neurosci 2002; 14:223-236; discussion 222.

-2 Zhang ZX, Roman GC, Hong Z, Wu CB, Qu QM, Huang JB, Zhou B, Geng ZP, Wu JX, Wen HB, Zhao H, Zahner GE: Parkinson's disease in China: prevalence in Beijing, Xian, and Shanghai. Lancet 2005;365:595-597.

-3 Paisan-Ruiz C, Saenz A, Lopez de Munain A, Marti I, Martinez Gil A, Marti-Masso JF, Perez-Tur J: Familial Parkinson's disease: clinical and genetic analysis of four Basque families. Ann Neurol 2005;57:365-372.

4 Lill CM: Genetics of Parkinson's disease. Mol Cell Probe 2016;30:386-396.

5 Polymeropoulos MH, Lavedan C, Leroy E, Ide SE, Dehejia A, Dutra A, Pike B, Root H, Rubenstein J, Boyer R, Stenroos ES, Chandrasekharappa S, Athanassiadou A, Papapetropoulos T, Johnson WG, Lazzarini AM, Duvoisin RC, Dilorio G, Golbe LI, Nussbaum RL: Mutation in the alpha-synuclein gene identified in families with Parkinson's disease. Science 1997;276:2045-2047.

6 Zimprich A, Biskup S, Leitner P, Lichtner P, Farrer M, Lincoln S, Kachergus J, Hulihan M, Uitti RJ, Calne DB, Stoessl AJ, Pfeiffer RF, Patenge N, Carbajal IC, Vieregge P, Asmus F, Muller-Myhsok B, Dickson DW, Meitinger T, Strom TM, Wszolek ZK, Gasser T: Mutations in LRRK2 cause autosomal-dominant Parkinsonism with pleomorphic pathology. Neuron 2004;44:601-607.
7 Kilarski LL, Pearson JP, Newsway V, Majounie E, Knipe MD, Misbahuddin A, Chinnery PF, Burn DJ, Clarke CE, Marion MH, Lewthwaite AJ, Nicholl DJ, Wood NW, Morrison KE, Williams-Gray CH, Evans JR, Sawcer SJ, Barker RA, Wickremaratchi MM, BenShlomo Y, Williams NM, Morris HR: Systematic review and UK-based study of PARK2 (parkin), PINK1, PARK7 (DJ-1) and LRRK2 in early-onset Parkinson's disease. Movement Disord 2012;27:1522-1529.

-8 Mata IF, Wedemeyer WJ, Farrer MJ, Taylor JP, Gallo KA: LRRK2 in Parkinson's disease: protein domains and functional insights. Trends Neurosci 2006;29:286-293.

-9 Bae JR, Lee BD: Function and dysfunction of leucine-rich repeat kinase 2 (LRRK2): Parkinson's disease and beyond. BMB Rep 2015;48: 243-248.

10 Taymans JM: The GTPase function of LRRK2. Biochem Soc Trans 2012;40:1063-1069.

11 Gotthardt K, Weyand M, Kortholt A, Van Haastert PJ, Wittinghofer A: Structure of the Roc-COR domain tandem of C. tepidum, a prokaryotic homologue of the human LRRK2 Parkinson kinase. ЕMBO J 2008;20;27:2239-2249.

12 Lesage S, Ibanez P, Lohmann E, Pollak P, Tison F, Tazir M, Leutenegger AL, Guimaraes J, Bonnet AM, Agid Y, Durr A, Brice A; French Parkinson's Disease Genetics Study Group: G2019S LRRK2 mutation in French and North African families with Parkinson's disease. Ann Neurol 2005;58:784-787.
13 Sheng Z, Zhang S, Bustos D, Kleinheinz T, Le Pichon CE, Dominguez SL, Solanoy HO, Drummond J, Zhang X, Ding X, Cai F, Song Q, Li X, Yue Z, van der Brug MP, Burdick DJ, Gunzner-Toste J, Chen H, Liu X, Estrada AA, Sweeney ZK, Scearce-Levie K, Moffat JG, Kirkpatrick DS, Zhu H: Ser1292 autophosphorylation is an indicator of LRRK2 kinase activity and contributes to the cellular effects of PD mutations. Sci Transl Med 2012;4: $164 \mathrm{ra} 161$.

14 Steger M, Tonelli F, Ito G, Davies P, Trost M, Vetter M, Wachter S, Lorentzen E, Duddy G, Wilson S, Baptista MA, Fiske BK, Fell MJ, Morrow JA, Reith AD, Alessi DR, Mann M: Phosphoproteomics reveals that Parkinson's disease kinase LRRK2 regulates a subset of Rab GTPases. Elife 2016; 5:pii:e12813.

15 Mills RD, Mulhern TD, Liu F, Culvenor JG, Cheng HC: Prediction of the repeat domain structures and impact of parkinsonism-associated variations on structure and function of all functional domains of leucine-rich repeat kinase 2 (LRRK2). Hum Mutat 2014;35:395412 .

16 Gloeckner CJ, Boldt K, von Zweydorf F, Helm S, Wiesent L, Sarioglu H, Ueffing M: Phosphopeptide analysis reveals two discrete clusters of phosphorylation in the N-terminus and the Roc domain of the Parkinson-disease associated protein kinase LRRK2. J Proteome Res 2010;9:1738-1745. 
17 Greggio E, Taymans JM, Zhen EY, Ryder J, Vancraenenbroeck R, Beilina A, Sun P, Deng J, Jaffe H, Baekelandt V, Merchant K, Cookson MR: The Parkinson's disease kinase LRRK2 autophosphorylates its GTPase domain at multiple sites. Biochem Biophys Res Commun 2009;389:449-454.

- 18 Liu Z, Mobley JA, DeLucas LJ, Kahn RA, West AB: LRRK2 autophosphorylation enhances its GTPase activity. FASEB J 2016;30:336-347.

19 Rudenko IN, Cookson MR: 14-3-3 proteins are promising LRRK2 interactors. Biochem J 2010;430:e5-e6.

20 Nichols RJ, Dzamko N, Morrice NA, Campbell DG, Deak M, Ordureau A, Macartney T, Tong Y, Shen J, Prescott AR, Alessi DR: 14-33 binding to LRRK2 is disrupted by multiple Parkinson's disease-associated mutations and regulates cytoplasmic localization. Biochem J 2010;430:393-404.

-21 Dzamko N, Deak M, Hentati F, Reith AD, Prescott AR, Alessi DR, Nichols RJ: Inhibition of LRRK2 kinase activity leads to dephosphorylation of Ser(910)/Ser(935), disruption of 14-3-3 binding and altered cytoplasmic localization. Biochem J 2010;430:405-413.

-22 Porter GW, Khuri FR, Fu H: Dynamic 14-3-3/ client protein interactions integrate survival and apoptotic pathways. Semin Cancer Biol 2006; 16:193-202.

-23 Li X, Wang QJ, Pan N, Lee S, Zhao Y, Chait BT, Yue Z: Phosphorylation-dependent 14-33 binding to LRRK2 is impaired by common mutations of familial Parkinson's disease. PLos One 2011;6:e17153.

24 Lavalley NJ, Slone SR, Ding H, West AB, Yacoubian TA: 14-3-3 Proteins regulate mutant LRRK2 kinase activity and neurite shortening. Hum Mol Genet 2016;25:109-122.

-25 Taymans JM, Van den Haute C, Baekelandt V: Distribution of PINK1 and LRRK2 in rat and mouse brain. J Neurochem 2006;98:951961.

26 Lee S, Liu HP, Lin WY, Guo H, Lu B: LRRK2 kinase regulates synaptic morphology through distinct substrates at the presynaptic and postsynaptic compartments of the drosophila neuromuscular junction. J Neurosci 2010;30:16959-16969.

27 Melrose HL, Dachsel JC, Behrouz B, Lincoln SJ, Yue M, Hinkle KM, Kent CB, Korvatska E, Taylor JP, Witten L, Liang YQ, Beevers JE, Boules M, Dugger BN, Serna VA, Gaukhman A, Yu X, Castanedes-Casey M, Braithwaite AT, Ogholikhan S, Yu N, Bass D, Tyndall G, Schellenberg GD, Dickson DW, Janus C, Farrer MJ: Impaired dopaminergic neurotransmission and microtubule-associated protein tau alterations in human LRRK2 transgenic mice. Neurobiol Dis 2010;40:503-517.

28 Herzig MC, Kolly C, Persohn E, Theil D, Schweizer T, Hafner T, Stemmelen C, Troxler TJ, Schmid P, Danner S, Schnell CR, Mueller M, Kinzel B, Grevot A, Bolognani F, Stirn M, Kuhn RR, Kaupmann K, van der Putten PH, Rovelli G, Shimshek DR: LRRK2 protein levels are determined by kinase function and are crucial for kidney and lung homeostasis in mice. Hum Mol Genet 2011;20:4209-4223.

29 Thevenet J, Pescini Gobert R, Hooft van Huijsduijnen R, Wiessner C, Sagot YJ: Regulation of LRRK2 expression points to a functional role in human monocyte maturation. PLos One 2011;6:e21519.

30 Ross OA, Soto-Ortolaza AI, Heckman MG, Aasly JO, Abahuni N, Annesi G, Bacon JA, Bardien S, Bozi M, Brice A, Brighina L, Van Broeckhoven C, Carr J, Chartier-Harlin MC, Dardiotis E, Dickson DW, Diehl NN, Elbaz A, Ferrarese C, Ferraris A, Fiske B, Gibson JM, Gibson R, Hadjigeorgiou GM, Hattori N, Ioannidis JP, Jasinska-Myga B, Jeon BS, Kim YJ, Klein C, Kruger R, Kyratzi E, Lesage S, Lin $\mathrm{CH}$, Lynch T, Maraganore DM, Mellick GD, Mutez E, Nilsson C, Opala G, Park SS, Puschmann A, Quattrone A, Sharma M, Silburn PA, Sohn YH, Stefanis L, Tadic V, Theuns J, Tomiyama H, Uitti RJ, Valente EM, van de Loo S, Vassilatis DK, Vilarino-Guell C, White LR, Wirdefeldt K, Wszolek ZK, Wu RM, Farrer MJ; Genetic Epidemiology Of Parkinson’s Disease (GEO-PD) Consortium: Association of LRRK2 exonic variants with susceptibility to Parkinson's disease: a case-control study. Lancet Neurol 2011;10:898-908.

- 31 Lesage S, Leclere L, Lohmann E, Borg M, Ruberg M, Durr A, Brice A: Frequency of the LRRK2 G2019S mutation in siblings with Parkinson's disease. Neurodegener Dis 2007;4: 195-198.

32 Lesage S, Durr A, Tazir M, Lohmann E, Leutenegger AL, Janin S, Pollak P, Brice A; French Parkinson's Disease Genetics Study Group: LRRK2 G2019S as a cause of Parkinson's disease in North African Arabs. N Engl J Med 2006;354:422-423.

33 Ozelius LJ, Senthil G, Saunders-Pullman R, Ohmann E, Deligtisch A, Tagliati M, Hunt AL, Klein C, Henick B, Hailpern SM, Lipton RB, Soto-Valencia J, Risch N, Bressman SB: LRRK2 G2019S as a cause of Parkinson's disease in Ashkenazi Jews. N Engl J Med 2006; 354:424-425.

34 Inzelberg R, Hassin-Baer S, Jankovic J: Genetic movement disorders in patients of Jewish ancestry. JAMA Neurol 2014;71:1567-1572.

35 Aasly JO, Vilarino-Guell C, Dachsel JC, Webber PJ, West AB, Haugarvoll K, Johansen KK, Toft M, Nutt JG, Payami H, Kachergus JM, Lincoln SJ, Felic A, Wider C, Soto-Ortolaza AI, Cobb SA, White LR, Ross OA, Farrer MJ: Novel pathogenic LRRK2 p.Asn1437His substitution in familial parkinson's disease. Mov Disord 2010;25:2156-2163.

-36 Puschmann A, Englund E, Ross OA, Vilarino-Guell C, Lincoln SJ, Kachergus JM, Cobb SA, Tornqvist AL, Rehncrona S, Widner H, Wszolek ZK, Farrer MJ, Nilsson C: First neuropathological description of a patient with Parkinson's disease and LRRK2 p.N1437H mutation. Parkinsonism Relat Disord 2012; 18:332-338.

- 37 Dachsel JC, Behrouz B, Yue M, Beevers JE, Melrose HL, Farrer MJ: A comparative study of
Lrrk2 function in primary neuronal cultures. Parkinsonism Relat Disord 2010;16:650-655.

38 MacLeod D, Dowman J, Hammond R, Leete $\mathrm{T}$, Inoue $\mathrm{K}$, Abeliovich $\mathrm{A}$ : The familial Parkinsonism gene LRRK2 regulates neurite process morphology. Neuron 2006;52:587-593.

-39 Parisiadou L, Xie CS, Cho HJ, Lin X, Gu XL, Long CX, Lobbestael E, Baekelandt V, Taymans JM, Sun LX, Cai HB: Phosphorylation of ezrin/radixin/moesin proteins by LRRK2 promotes the rearrangement of actin cytoskeleton in neuronal morphogenesis. J Neurosci 2009;29:13971-13980.

40 Winner B, Melrose HL, Zhao C, Hinkle KM, Yue M, Kent C, Braithwaite AT, Ogholikhan S, Aigner R, Winkler J, Farrer MJ, Gage FH: Adult neurogenesis and neurite outgrowth are impaired in LRRK2 G2019S mice. Neurobiol Dis 2011;41:706-716.

41 Kett LR, Boassa D, Ho CC, Rideout HJ, Hu J, Terada M, Ellisman M, Dauer WT: LRRK2 Parkinson disease mutations enhance its microtubule association. Hum Mol Genet 2012; 21:890-899.

42 Godena VK, Brookes-Hocking N, Moller A, Shaw G, Oswald M, Sancho RM, Miller CC, Whitworth AJ, De Vos KJ: Increasing microtubule acetylation rescues axonal transport and locomotor deficits caused by LRRK2 Roc-COR domain mutations. Nat Commun 2014;5:5245.

43 Law BM, Spain VA, Leinster VH, Chia R, Beilina A, Cho HJ, Taymans JM, Urban MK, Sancho RM, Blanca Ramírez M, Biskup S, Baekelandt V, Cai H, Cookson MR, Berwick DC, Harvey K: A direct interaction between Leucine-rich repeat kinase 2 and specific beta-tubulin isoforms regulates tubulin acetylation. J Biol Chem 2014;289:895-908.

-44 Shin N, Jeong H, Kwon J, Heo HY, Kwon JJ, Yun HJ, Kim CH, Han BS, Tong Y, Shen J, Hatano T, Hattori N, Kim KS, Chang S, Seol W: LRRK2 regulates synaptic vesicle endocytosis. Exp Cell Res 2008;314:2055-2065.

45 Carney DS, Davies BA, Horazdovsky BF: Vps9 domain-containing proteins: activators of Rab5 GTPases from yeast to neurons. Trends Cell Biol 2006;16:27-35.

46 Rivero-Rios P, Gomez-Suaga P, Fernandez B Madero-Perez J, Schwab AJ, Ebert AD, Hilfiker S: Alterations in late endocytic trafficking related to the pathobiology of LRRK2linked Parkinson's disease. Biochem Soc Trans 2015;43:390-395.

47 Dzamko N, Inesta-Vaquera F, Zhang J, Xie C, Cai HB, Arthur S, Tan L, Choi H, Gray N, Cohen P, Pedrioli P, Clark K, Alessi DR: The IkappaB kinase family phosphorylates the Parkinson's disease kinase LRRK2 at Ser935 and Ser910 during Toll-Like Receptor Signaling. PLoS One 2012;7:e39132.

48 Inestrosa NC, Arenas E: Emerging roles of Wnts in the adult nervous system. Nat Rev Neurosci 2010;11:77-86.

49 Sancho RM, Law BM, Harvey K: Mutations in the LRRK2 Roc-COR tandem domain link Parkinson's disease to Wnt signalling pathways. Hum Mol Genet 2009; 18:3955-3968. 
50 Berwick DC, Harvey K: LRRK2 functions as a Wnt signaling scaffold, bridging cytosolic proteins and membrane-localized LRP6. Hum Mol Genet 2012;21:4966-4979.

-51 Nixon-Abell J, Berwick DC, Granno S, Spain VA, Blackstone C, Harvey K: Protective LRRK2 R1398H variant enhances GTPase and Wnt signaling activity. Front Mol Neurosci 2016;9:18.

52 Berwick DC, Javaheri B, Wetzel A, Hopkinson M, Nixon-Abell J, Granno S, Pitsillides AA, Harvey K: Pathogenic LRRK2 variants are gain-of-function mutations that enhance LRRK2-mediated repression of betacatenin signaling. Mol Neurodegener 2017; 12:9.

53 Salasova A, Yokota C, Potesil D, Zdrahal Z, Bryja V, Arenas E: A proteomic analysis of LRRK2 binding partners reveals interactions with multiple signaling components of the WNT/PCP pathway. Mol Neurodegener 2017;12:54.

54 Ohta E, Nihira T, Uchino A, Imaizumi Y, Okada Y, Akamatsu W, Takahashi K, Hayakawa $H$, Nagai $M$, Ohyama $M$, Ryo $M$, Ogino M, Murayama S, Takashima A, Nishiyama K, Mizuno Y, Mochizuki H, Obata F, Okano H: I2020T mutant LRRK2 iPSC-derived neurons in the Sagamihara family exhibit increased Tau phosphorylation through the AKT/GSK$3 \beta$ signaling pathway. Hum Mol Genet 2015; 24:4879-4900.

55 Covy JP, Giasson BI: Identification of compounds that inhibit the kinase activity of leucine-rich repeat kinase 2. Biochem Biophys Res Commun 2009;387:419-420.

56 Deng XM, Dzamko N, Prescott A, Davies P, Liu QS, Yang QK, Lee JD, Patricelli MP, Nomanbhoy TK, Alessi DR, Gray NS: Characterization of a selective inhibitor of the Parkinson's disease kinase LRRK2. Nat Chem Biol 2011;7:203-205.

-57 Luerman GC, Nguyen C, Samaroo H, Loos P, Xi H, Hurtado-Lorenzo A, Needle E, Stephen Noell G, Galatsis P, Dunlop J, Geoghegan KF, Hirst WD: Phosphoproteomic evaluation of pharmacological inhibition of leucine-rich repeat kinase 2 reveals significant off-target effects of LRRK-2-IN-1. J Neurochem 2014; 128:561-576.

-58 Ramsden N, Perrin J, Ren Z, Lee BD, Zinn N, Dawson VL, Tam D, Bova M, Lang M, Drewes G, Bantscheff M, Bard F, Dawson TM, Hopf C: Chemoproteomics-based design of potent LRRK2-selective lead compounds that attenuate parkinson's disease-related toxicity in human neurons. ACS Chem Biol 2011;6: 1021-1028.

59 Choi HG, Zhang J, Deng X, Hatcher JM, Patricelli MP, Zhao Z, Alessi DR, Gray NS: Brain penetrant LRRK2 inhibitor. ACS Med Chem Lett 2012;3:658-662.

-60 Reith AD, Bamborough P, Jandu K, Andreotti D, Mensah L, Dossang P, Choi HG, Deng X, Zhang J, Alessi DR, Gray NS: GSK2578215A; A potent and highly selective 2-arylmethy-
loxy-5-substitutent-N-arylbenzamide LRRK2 kinase inhibitor. Bioorg Med Chem Lett 2012; 22:5625-5629.

61 Estrada AA, Liu X, Baker-Glenn C, Beresford A, Burdick DJ, Chambers M, Chan BK, Chen H, Ding X, DiPasquale AG, Dominguez SL, Dotson J, Drummond J, Flagella M, Flynn S, Fuji R, Gill A, Gunzner-Toste J, Harris SF, Heffron TP, Kleinheinz T, Lee DW, Le Pichon CE, Lyssikatos JP, Medhurst AD, Moffat JG, Mukund S, Nash K, Scearce-Levie K, Sheng Z, Shore DG, Tran T, Trivedi N, Wang S, Zhang S, Zhang X, Zhao G, Zhu H, Sweeney ZK: Discovery of highly potent, selective, and brainpenetrable Leucine-rich repeat kinase 2 (LRRK2) small molecule inhibitors. J Med Chem 2012;55:9416-9433.

62 Hatcher JM, Zhang J, Choi HG, Ito G, Alessi DR, Gray NS: Discovery of a pyrrolopyrimidine (JH-II-127), a highly potent, selective, and brain penetrant LRRK2 inhibitor. ACS Med Chem Lett 2015;6:584-589.

63 Henderson JL, Kormos BL, Hayward MM, Coffman KJ, Jasti J, Kurumbail RG, Wager TT, Verhoest PR, Noell GS, Chen Y, Needle E, Berger Z, Steyn SJ, Houle C, Hirst WD, Galatsis P: Discovery and preclinical profiling of 3-[4-(morpholin-4-yl)-7H-pyrrolo[2,3-d] pyrimidin-5-yl]benzonitrile (PF-06447475), a highly potent, selective, brain penetrant, and in vivo active LRRK2 kinase inhibitor. J Med Chem 2015;58:419-432.

64 Fell MJ, Mirescu C, Basu K, Cheewatrakoolpong B, DeMong DE, Ellis JM, Hyde LA, Lin Y, Markgraf CG, Mei H, Miller M, Poulet FM, Scott JD, Smith MD, Yin Z, Zhou X, Parker EM, Kennedy ME, Morrow JA: MLi-2, a potent, selective, and centrally active compound for exploring the therapeutic potential and safety of LRRK2 kinase inhibitions. J Pharmacol Exp Ther 2015;355:397-409.

65 Saez-Atienzar S, Bonet-Ponce L, Blesa JR, Romero FJ, Murphy MP, Jordan J, Galindo MF: The LRRK2 inhibitor GSK2578215A induces protective autophagy in SH-SY5Y cells: involvement of Drp-1-mediated mitochondrial fission and mitochondrial-derived ROS signaling. Cell Death Dis 2014;5:e1368.

66 Mendivil-Perez M, Velez-Pardo C, JimenezDel-Rio M: Neuroprotective effect of the LRRK2 kinase inhibitor PF-06447475 in human nerve-like differentiated cells exposed to oxidative stress stimuli: implications for Parkinson's disease. Neurochem Res 2016;41: 2675-2692.

67 Qin Q, Zhi LT, Li XT, Yue ZY, Li GZ, Zhang H: Effects of LRRK2 Inhibitors on Nigrostriatal Dopaminergic Neurotransmission. CNS Neurosci Ther 2017;23:162-173.

68 Volpicelli-Daley LA, Abdelmotilib H, Liu Z, Stoyka L, Daher JP, Milnerwood AJ, Unni VK, Hirst WD, Yue Z, Zhao HT, Fraser K, Kennedy RE, West AB: G2019S-LRRK2 expression augments $\alpha$-Synuclein sequestration into inclusions in neurons. J Neurosci 2016; 36:7415-7427.
69 Daher JP, Abdelmotilib HA, Hu X, VolpicelliDaley LA, Moehle MS, Fraser KB, Needle E, Chen Y, Steyn SJ, Galatsis P, Hirst WD, West AB: Leucine-rich Repeat Kinase 2 (LRRK2) pharmacological inhibition abates alphasynuclein gene-induced neurodegeneration. J Biol Chem 2015;290:19433-19444.

70 Longo F, Mercatelli D, Novello S, Arcuri L, Brugnoli A, Vincenzi F, Russo I, Berti G, Mabrouk OS, Kennedy RT, Shimshek DR, Varani K, Bubacco L, Greggio E, Morari M: Age-dependent dopamine transporter dysfunction and Serine129 phospho-alpha-synuclein overload in G2019S LRRK2 mice. Acta Neuropathol Com 2017;5:22.

71 Rouaud T, Clairembault T, Coron E, Neunlist M, Anheim M, Derkinderen P: Enteric alphasynuclein pathology in LRRK2-G2019S Parkinson's disease. Parkinsonism Relat Disord 2017;40:83-84.

72 Dusonchet J, Kochubey O, Stafa K, Young SM Jr, Zufferey R, Moore DJ, Schneider BL, Aebischer P: A rat model of progressive nigral neurodegeneration induced by the Parkinson's disease-associated G2019S mutation in LRRK2. J Neurosci 2011;31:907-912.

73 Tsika E, Nguyen AP, Dusonchet J, Colin P, Schneider BL, Moore DJ: Adenoviral-mediated expression of G2019S LRRK2 induces striatal pathology in a kinase-dependent manner in a rat model of Parkinson's disease. Neurobiol Dis 2015;77:49-61.

74 Hinkle KM, Yue M, Behrouz B, Dachsel JC, Lincoln SJ, Bowles EE, Beevers JE, Dugger B, Winner B, Prots I, Kent CB, Nishioka K, Lin WL, Dickson DW, Janus CJ, Farrer MJ, Melrose HL: LRRK2 knockout mice have an intact dopaminergic system but display alterations in exploratory and motor co-ordination behaviors. Mol Neurodegener 2012; $7: 25$.

75 Baptista MA, Dave KD, Sheth NP, De Silva SN, Carlson KM, Aziz YN, Fiske BK, Sherer TB, Frasier MA: A strategy for the generation, characterization and distribution of animal models by The Michael J. Fox Foundation for Parkinson's Research. Dis Model Mech 2013; 6:1316-1324.

76 Tong Y, Yamaguchi H, Giaime E, Boyle S, Kopan R, Kelleher RJ 3rd, Shen J: Loss of leucinerich repeat kinase 2 causes impairment of protein degradation pathways, accumulation of alpha-synuclein, and apoptotic cell death in aged mice. Proc Natl Acad Sci USA 2010;107: 9879-9884.

-77 Fuji RN, Flagella M, Baca M, Baptista MA, Brodbeck J, Chan BK, Fiske BK, Honigberg L, Jubb AM, Katavolos P, Lee DW, Lewin-Koh SC, Lin TR, Liu X, Liu S, Lyssikatos J, O'Mahony J, Reichelt M, Roose-Girma M, Sheng Z, Sherer T, Smith A, Solon M, Sweeney ZK, Tarrant J, Urkowitz A, Warming S, Yaylaoglu M, Zhang S, Zhu H, Estrada AA, Watts RJ: Effect of selective LRRK2 kinase inhibition on nonhuman primate lung. Sci Transl Med 2015;7:273ra15. 